UNDERGROUND MINING ENGINEERING 37 (2020) 25-31 $\quad$ UDK 62

Original scientific paper

\title{
GAS CONTROL IN TG MOTOR REGION IN LONGWALL GASSY MINES
}

\author{
Krishna Tanguturi' ${ }^{1}$, Rao Balusu', Bharath Belle ${ }^{2}{ }^{3}$
}

Received: July 15,2020

Accepted: August 28, 2020

\begin{abstract}
A number of longwall mines suffer significant gas delays due to high methane gas concentration levels (i.e. above $1.0 \%$ statutory limit for methane gas level) near the tailgate (TG) motor area of the longwall face. Therefore, in addition to development of effective goaf gas drainage and management strategies for highly gassy mines, development of face control strategies to minimize methane gas concentration levels near the tailgate motor of the longwall face is highly critical to achieve high production rates in high capacity longwall mines. To address this issue, detailed CFD models of longwall face were developed and extensive modelling simulations were carried out to investigate the effectiveness of various control options on gas concentration distribution near the tailgate motor area. To investigate the effect of mining and ventilation parameters on effectiveness of various control strategies, simulations were carried out with CFD models of Mine A. The details and results of all these studies are presented in this paper.
\end{abstract}

Keywords: Tailgate (TG), TG drive, Curtains, Goaf, Longwall

\section{INTRODUCTION}

Goaf gas emissions have increased substantially over the years and are set to increase in the near future due to higher production rates, increased depth of mine and industry's trend towards wider and longer panels. In highly gassy mining conditions and in coal seams prone to spontaneous combustion, management of these two key issues is critical for successful operation of longwalls, particularly in longer panels. Theoretically, gas management should be such that the methane gas drainage rate from goaf holes should be equivalent to the goaf gas emissions rate. It's challenging and practically not possible develop such ideal gas management systems. Generally, the undrained goaf gas will be drained through the ventilation air and resulting in high methane gas levels in the TG region. When the concentrations reach $2 \%$, the sensor loaded on the TG equipment's trips off the TG drive and hamper all the longwall operations.

${ }^{1}$ CSIRO Energy, 1Technology Court, Kenmore, 4068 Australia

${ }^{2}$ Anglo American Coal, Australia

${ }^{3}$ University of NSW, Australia

E-mails: krishna.tanguturi@csiro.au rao.balusu@csiro.au 
CFD modelling has been used in the coal mining industry in a number of areas by various researchers. In the last two decades, CFD techniques were widely used to model gas and dust flows in longwall mines. Aziz et al (1993) used numerical techniques to understand the ventilation mechanisms, gas and dust distributions in coal mines. Balusu et al (2002, 2004) carried out numerical investigations for understanding goaf gas distribution in gassy mines and proposed various inertisation strategies for prevention of spontaneous combustion in those mines. Two-dimensional CFD models based on the theory of natural convection and heat transfer in porous media were used to study the flow and temperature fields in underground coal fires (Huang et al. 2001). National Institute for Occupational Safety and Health (NIOSH) and Mine Safety and Health Administration (MSHA) investigated the temperature characteristics of mine fire (Trevist et al. 2009). Coal dust explosions are one of the most significant hazards in underground mines. A series of comprehensive studies were conducted (Proud et al. 2015; Collecutt et al. 2009) using CFD simulations to model coal dust explosions and the effectiveness of active explosion barriers. Various other investigations simulating auxiliary ventilation layouts in rapid heading development (Monoley et al. 1998), mine fires and explosions (Brune and Saki, 2017), control of methane and spontaneous heating (Yuan and Smith, 2009), spontaneous combustion and heating in longwall (Yuan and Smith, 2009), and in other applications in mineral processing (Fletcher et al. 1995).

CFD techniques were used for investigating the gas management options near the TG region of the longwall top coal caving face (Tanguturi and Balusu, 2014). In this paper, the results of the research work carried out for controlling the gas in the TG regions using CFD techniques are presented. Initially, investigations were carried out for determining the gas concentration near the TG motor and later, various gas management strategies using curtains at various locations in the longwall were investigated numerically.

\section{NOMENCLATURE}

\begin{tabular}{|c|c|c|c|}
\hline $\overrightarrow{\boldsymbol{V}}$ & Velocity Vector & $\boldsymbol{\mu}$ & $\begin{array}{l}\text { Coefficient of molecular } \\
\text { viscosity }\end{array}$ \\
\hline $\mathbf{Y}$ & Mass fraction of the species & $\rho$ & Mass density \\
\hline $\overrightarrow{\boldsymbol{f}}$ & Body force vector per unit mass & $\dot{\omega}$ & $\begin{array}{l}\text { Rate of generation of mass per } \\
\text { unit mass }\end{array}$ \\
\hline $\overrightarrow{\boldsymbol{S}}$ & Source Vector in the momentum equation per unit mass & $\tau$ & Stress Tensor \\
\hline $\mathbf{p}$ & Static Pressure & $\delta_{i j}$ & Kronecker delta \\
\hline $\boldsymbol{u}_{\boldsymbol{i}}$ & Velocity along $i / x$ direction & $\varepsilon$ & Specific dissipation rate \\
\hline $\boldsymbol{u}_{j}$ & Velocity along $j / y$ direction & $\boldsymbol{\kappa}$ & Turbulent kinetic energy \\
\hline$x$ & Space direction & $\mu_{T}$ & Eddy Viscosity \\
\hline$D_{m}$ & Coefficient of mass diffusivity & $C_{i j}$ & $\begin{array}{l}\text { Inertia Resistance Coefficient } \\
\text { in Porous matrix }\end{array}$ \\
\hline$D_{i j}$ & Viscous Resistance Coefficient in Porous matrix & & \\
\hline
\end{tabular}




\section{CFD MODEL DEVELOPMENT}

The CFD models were developed based on the dimensions of the longwall panel at Mine A. Geometric coordinates from the working seam floor contours were used for developing the CFD models. The longwall panel width is $310 \mathrm{~m}$ and the roadway width on both maingate (MG) and tailgate (TG) sides of the face is $5.4 \mathrm{~m}$. The longwall extraction thickness is $3.6 \mathrm{~m}$, which also represents the face height in the model. The goaf height up to $80 \mathrm{~m}$ above the working seam and the floor strata down to $12 \mathrm{~m}$ below the working seam is included in the models. The layout of the CFD model is shown in Figure 1.

MG and TG cut-throughs of $5 \mathrm{~m}$ in width and $75 \mathrm{~m}$ in length have been incorporated into the CFD models, and these cut-throughs were spaced at $125 \mathrm{~m}$ intervals along the panel in the models. One rear shaft of $2.1 \mathrm{~m}$ diameter has also been included in the CFD model, which is located on the TG side at the start-up areas of the models. A number of goaf gas drainage holes of $0.3 \mathrm{~m}$ diameter at different locations were incorporated into the micro model to investigate the effect of various goaf gas drainage strategies. Each individual goaf hole can be switched 'ON' and 'OFF' in various simulations, depending on the goaf gas drainage to be investigated.

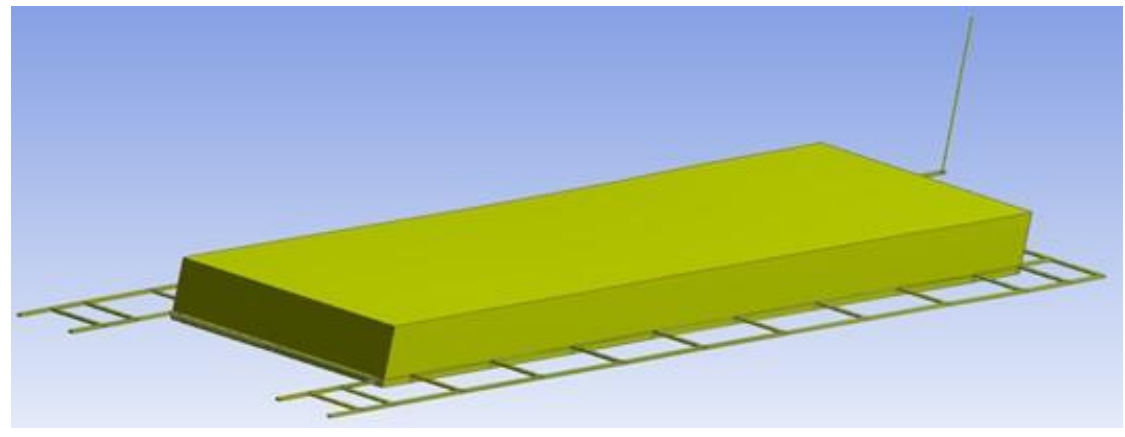

(a) View from the MG end

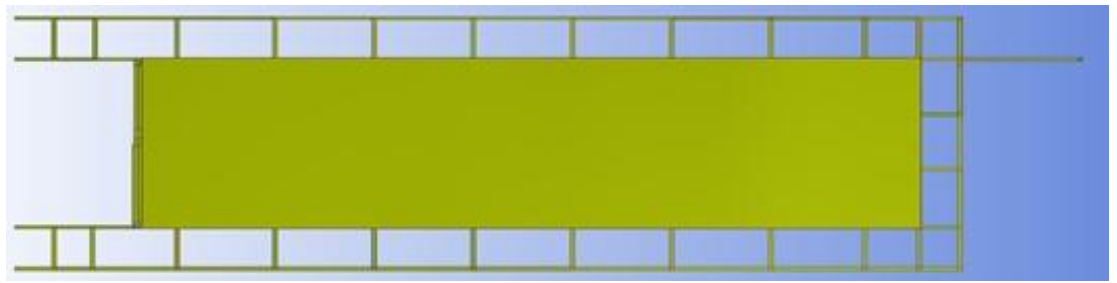

(b) Plan view

Figure 1 CFD model of the longwall panel - Mine A 
After development of the basic configuration for the CFD model, all the longwall face equipment was also incorporated into the model, based on the equipment drawings of the longwall shields, MG and TG shields, BSL, and shearer. The CFD models also contain details of the longwall face such as the BSL at the MG side of the panel, shearer located at the mid face, transitional shields at MG and TG sides of the face and the AFC motor drives at MG and TG areas etc., as shown in Figure 2.

\section{BOUNDARY CONDITIONS- MINE A}

Mine A uses U ventilation system for longwall panels. The ventilation layout and actual airflow quantities of Mine A are used in CFD simulations, as shown in Figure 3. In the CFD model, the velocity inlet boundary conditions were specified at the MG intake roadway $\left(70 \mathrm{~m}^{3} / \mathrm{s}\right)$ and also at the TG intake roadways $\left(40 \mathrm{~m}^{3} / \mathrm{s}\right)$. An outlet velocity condition was specified at the MG roadway $\left(30 \mathrm{~m}^{3} / \mathrm{s}\right)$ and a free outflow condition was specified at the TG end for the total ventilation quantity of $80 \mathrm{~m}^{3} / \mathrm{s}$ leaving the face. The rear shaft which was incorporated as intake shaft was closed in the modelling simulations. The permeability distribution in the goaf area varies considerably at various locations depending on the stress distribution, and it ranged from 10e3 millidarcy (md) to $10 \mathrm{e} 10 \mathrm{md}$ in the goaf area and goes up to $10 \mathrm{e} 12 \mathrm{md}$ in the collapsed roadways just behind the face.

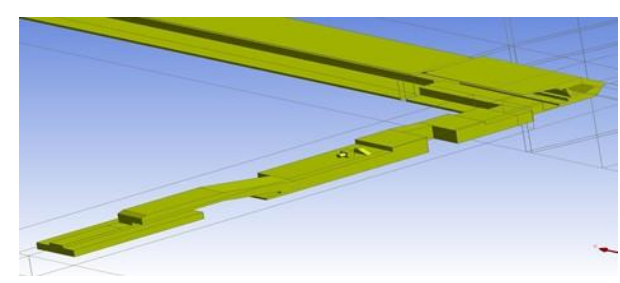

(a) MG side equipment's and transition shields

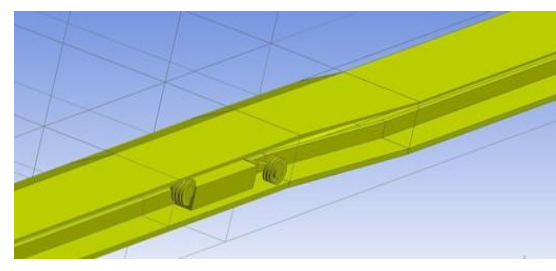

(b) Shearer location at the mid of the face

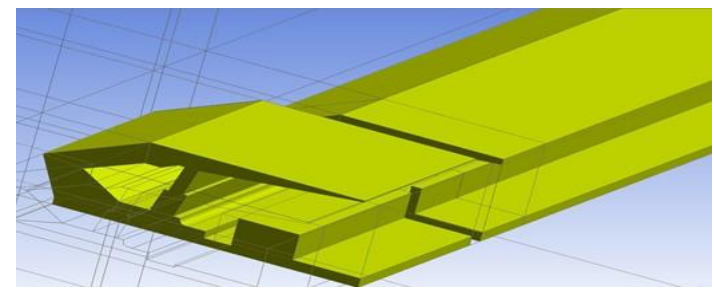

(c) TG transition shields and TG motor drive

Figure 2 Longwall equipment configuration in CFD model - Mine A 


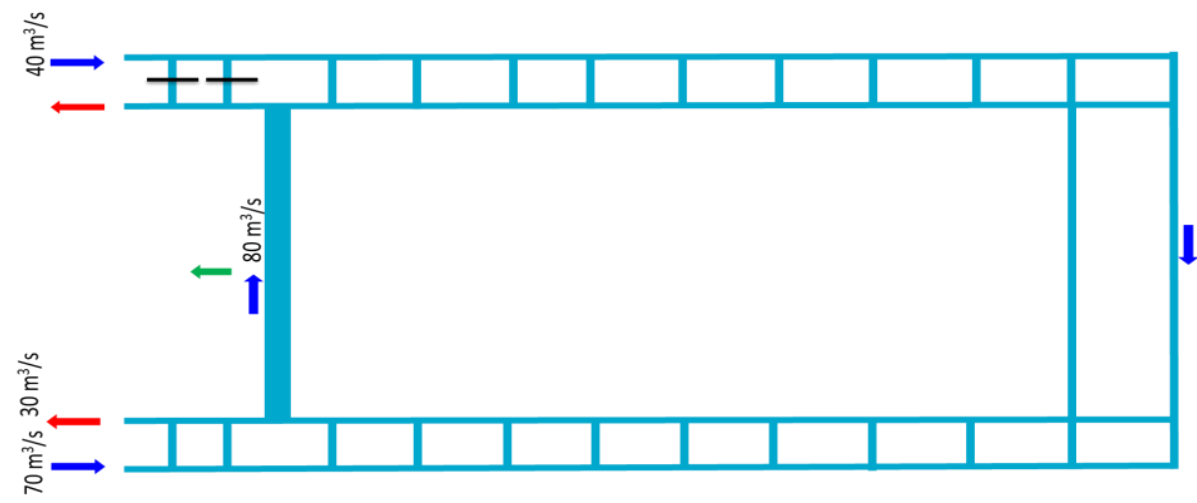

Figure 3 Longwall ventilation layout - Mine A

\section{MATHEMATICAL MODEL}

The instantaneous conservative equations i.e., continuity, Navier Stokes and the species equations were solved numerically using finite volume discretisation techniques (Patankar, 1980). These equations are solved in the goaf region where the flow is laminar. Note that the goaf region is treated as porous media with resistances varying in all the three directions.

Continuity equation for incompressible air flow

$$
\nabla \cdot \vec{V}=0.0
$$

Steady State Navier Stokes Equation for incompressible flow

$$
(\vec{V} \bullet \nabla) \rho \vec{V}=-\nabla p+\mu \nabla^{2} \vec{V}+\rho \vec{f}+\vec{S}
$$

Steady State Species Transport Equation

$$
\left(\vec{V}_{s} \bullet \nabla\right) \rho Y_{s}=D_{m_{s}} \nabla^{2} Y+\dot{\omega}_{s}
$$

where subscript s represents properties of $\mathrm{O}_{2}, \mathrm{CH}_{4}$ and $\mathrm{N}_{2}$.

Turbulence Modelling

The flow is assumed to be turbulent in the face region and the time averaged equations are solved. Two equation k-epsilon model was used to determine the eddy viscosity.

Time Averaged Governing Equations 
Continuity Equation:

$$
\nabla \cdot \overrightarrow{\bar{V}}=0.0
$$

Reynolds Averaged Navier Stokes Equation:

$$
(\overrightarrow{\bar{V}} \bullet \nabla) \rho \overrightarrow{\bar{V}}=-\nabla \bar{P}+\mu \nabla^{2} \overrightarrow{\bar{V}}+\nabla: \tau_{R}
$$

where $\tau_{R}$ is the Reynolds stress tensor.

Turbulent Kinetic Energy- $k$ equation:

$$
\rho \overline{u_{j}} \frac{\partial k}{\partial x_{j}}=\tau_{i j} \frac{\partial \overline{u_{i}}}{\partial x_{j}}+\frac{\partial}{\partial x_{j}}\left(\left(\mu+\frac{\mu_{T}}{\sigma_{k}}\right) \frac{\partial k}{\partial x_{j}}\right)-\rho \varepsilon
$$

where subscript $\mathrm{j}$ represents Einstein summation notation.

Turbulent dissipation- Eequation:

$$
\rho \overline{u_{j}} \frac{\partial \varepsilon}{\partial x_{j}}=C_{\mu 1} \tau_{i j} \frac{\partial \overline{u_{i}}}{\partial x_{j}}+\frac{\partial}{\partial x_{j}}\left(\left(\mu+\frac{\mu_{T}}{\sigma_{\varepsilon}}\right) \frac{\partial \varepsilon}{\partial x_{j}}\right)-C_{\mu 2} \rho \frac{\varepsilon}{k^{2}}
$$

where $\mathrm{C}_{\mu 1}$ and $\mathrm{C}_{\mu 2}$ are closure coefficient.

Reynolds Stress:

$$
\tau_{i j}=\mu_{T}\left(\frac{\partial \overline{u_{i}}}{\partial x_{j}}+\frac{\partial \overline{u_{j}}}{\partial x_{i}}\right)-\frac{2}{3} \rho k \delta_{i j}
$$

where $\mu_{T}$ is the eddy viscosity and $\delta_{i j}$ is Kronecker delta.

Eddy Viscosity:

$$
\mu_{T}=c_{\mu} \rho \frac{k^{2}}{\varepsilon}
$$

where $c_{\mu}$ is closure coefficient which is equal to 0.07 .

The coupling between the velocity and pressure is done by SIMPLE algorithm.

\section{Porous media model}

The porous media model was used to simulate the flow though the porous goaf regions by the addition of a momentum source term to the standard fluid flow equations. The source term is composed of two parts: a viscous loss term (Darcy law), and an inertial loss term: 


$$
\vec{S}=-\left(\sum_{j=1}^{3} D_{i j} \mu \vec{V}+\sum_{j=1}^{3} C_{i j} \frac{1}{2} \rho|\vec{V}| \vec{V}\right)
$$

Where $\vec{S}$ is the source vector, $|\vec{V}|$ is the magnitude of the velocity and $D$ and $C$ are prescribed functions which are related to the distributions of permeability and inertial resistance coefficient of the longwall goaf. This momentum sink contributes to the pressure gradient in the porous cell, creating a pressure drop that is proportional to the fluid velocity in the cell. In the CFD model, the incorporation of goaf spatial permeability distribution and gas emission are via user defined function (UDF) that is linked to solver.

\section{MODEL VALIDATION}

In the base case model simulations, actual geometry and operating conditions of the initial longwall panels at Mine A were used. Boundary conditions as discussed in section Figure 3 are used in the base case simulations. The total goaf gas emissions were around $3,000 \mathrm{l} / \mathrm{s}$ of methane, with total goaf gas drainage flow rates of around 3,300 1/s. The results of base case simulations along with field measured values are presented in Figure 4 , showing comparison of oxygen and methane gas concentration levels at various locations behind the longwall face. 


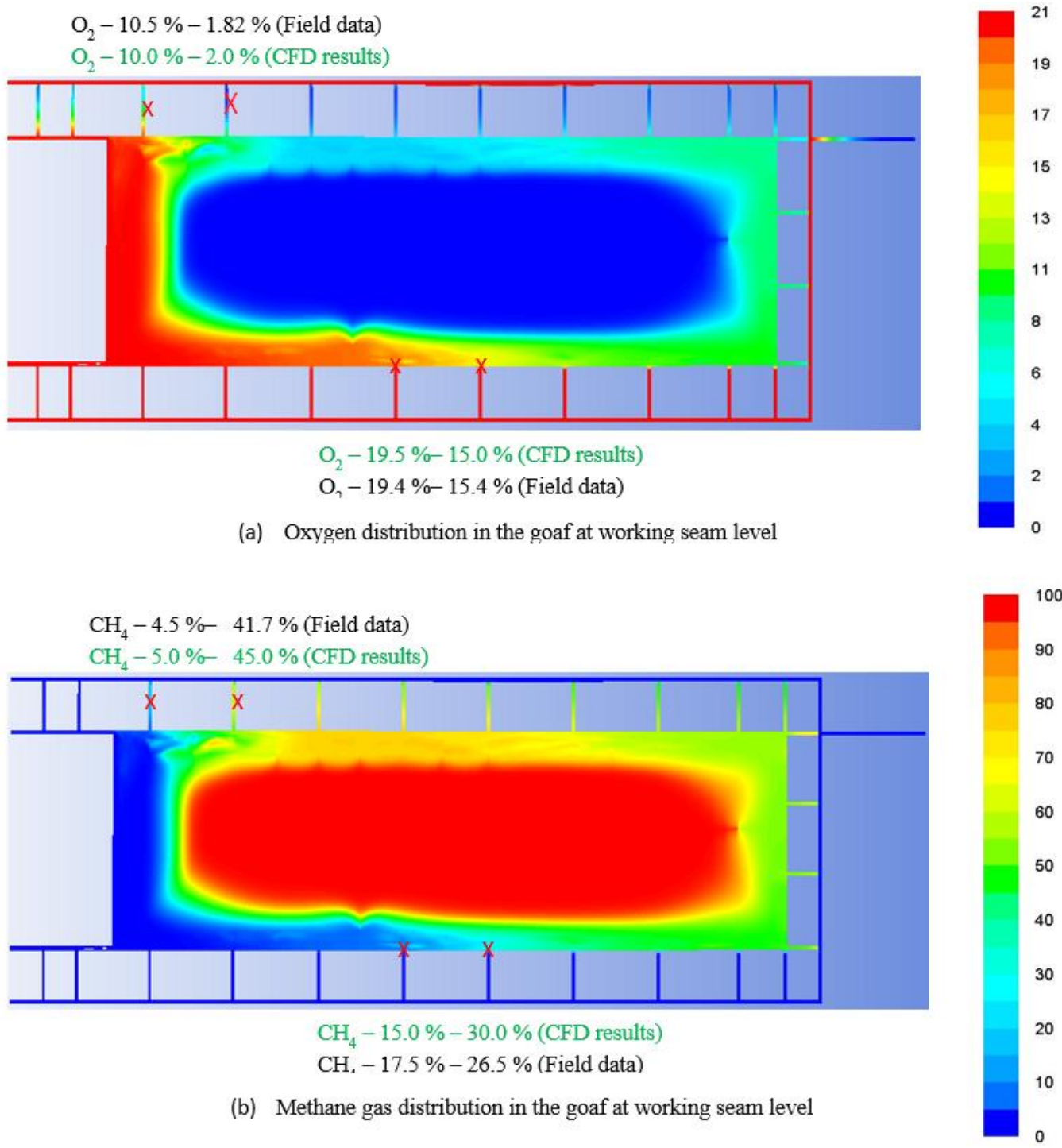

Figure 4 Comparison of CFD simulation results and field data - Mine A

Simulation results show that oxygen ingress is high on the maingate side, with oxygen concentration levels over $15 \%$ even at $500 \mathrm{~m}$ behind the longwall face (Figure 4 (a). Results show high methane gas concentration levels on the tailgate side of the panel due to gas buoyancy effects. Comparison and analyses of the results presented in Figure 4a and Figure $4 \mathrm{~b}$ shows that simulation results are in close agreement with the field measured data from Mine A.

Based on the results of extensive CFD modelling investigations carried out during the course of the project, it was identified that a new goaf gas drainage strategy involving 
additional goaf holes on MG side would contribute to a significant increase in goaf gas drainage rates in longwall panels. These optimum goaf gas drainage strategies were implemented at Mine A as field demonstration studies. The results of the field studies showing the methane gas concentration levels and flow rates in various goaf holes located on TG and MG sides, and at start-up areas are presented in Figure 5. Field results show that methane gas concentration levels varies between 37\% and 68\% in TG goaf gas drainage holes, $92 \%$ in MG goaf hole, and $80 \%$ in the start-up area goaf hole. Analyses of the field data shows that the methane gas concentration levels at the mine site are in close agreement with the simulated values.

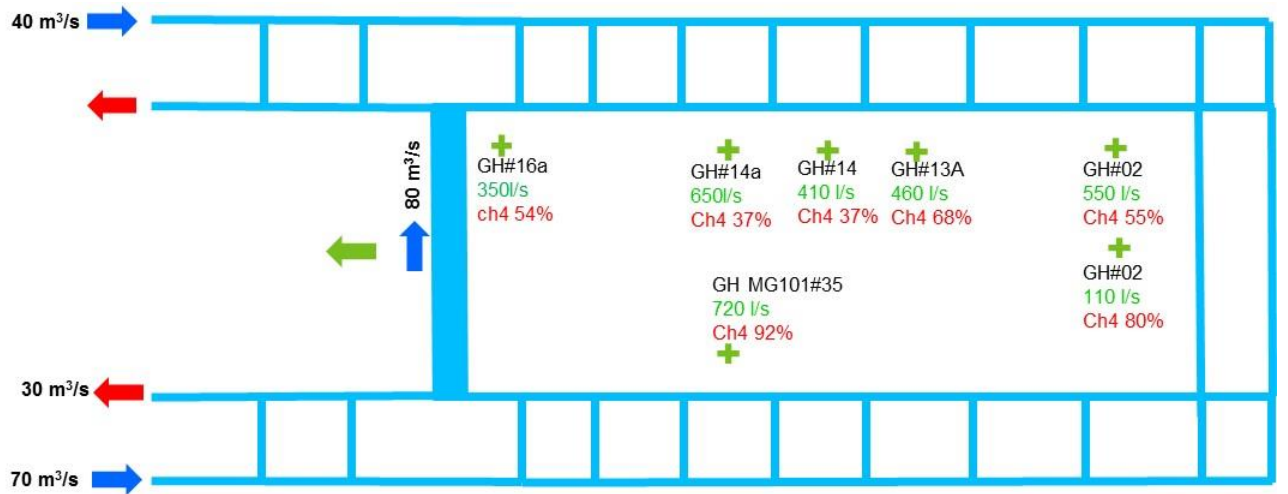

Figure 5 Field study results - Goaf holes performance data - Mine A

\section{RESULTS AND DISCUSSIONS}

Analyses of the goaf gas distribution patterns presented in the above section indicates that in addition to goaf gas drainage there is a need to develop additional control strategies to manage gas concentration levels at the TG motor area. Based on the above gas distribution patterns, it was identified that one of the practicable ways to manage TG goaf gas distribution is to modify airflow patterns near the TG motor area. To achieve the objective of reduced gas levels at the TG motor area, a number of control options involving various curtain configurations were investigated. The results of various investigations showing the effect of various control strategies on TG gas distribution patterns under Mine A conditions are presented in this section.

The location and configuration of various curtain options is presented in Figure 6. All the curtains are oriented across the face, i.e. perpendicular to the airflow direction. The first three configurations involve installation of different size curtains in the chock shields at approximately $2 \mathrm{~m}$ to $5 \mathrm{~m}$ upstream of the TG motor, as shown in Figure 7 . The fourth configuration involves installation of additional curtain in the transition shield adjacent to the TG motor. In summary, the configuration 1 involves installation of curtain 
above AFC, as shown in Figure 6 (a); configuration 2 involves installation of a long curtain over AFC and walkway region, as shown in Figure 6 (b); configuration 3 involves installation of a curtain in front walkway region of the chock shield, as shown in Figure 6 (c); and the fourth configuration involves installation of a curtain in walkway region of transition shield adjacent to the TG motor, as shown in Figure 6 (d).

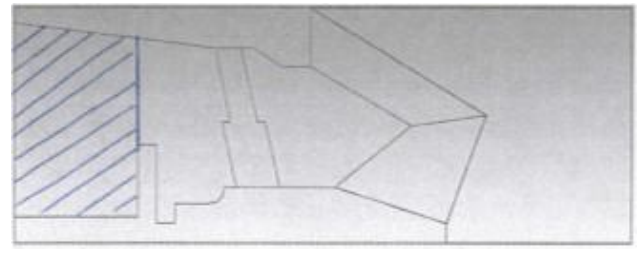

(a) Curtain above AFC

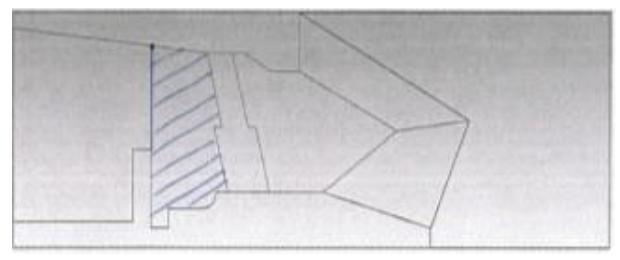

(c) Small size curtain in walkway region

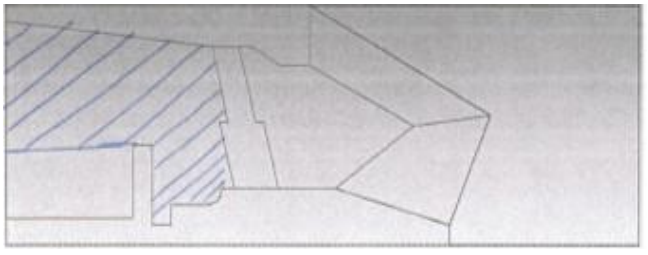

(b)Large size curtain above half $\mathrm{AFC}$ and in the walkway region

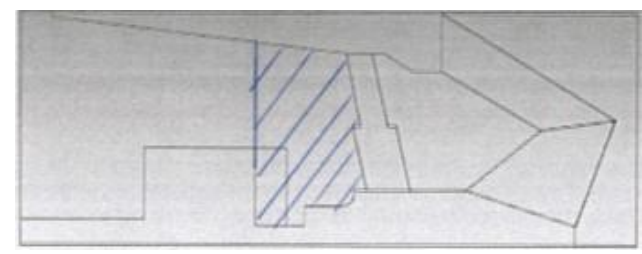

(d) Curtain in the walkway region of transitional shield

Figure 6 Various curtain configurations for gas control around the TG motor area

Extensive modelling investigations were carried out with above individual curtain configurations and a combination of curtain configurations to investigate their effect on gas distribution patterns at the TG motor area. The results of a few key investigations are presented in the following sub-sections.

This control option 1 involves configuration 2 (Figure 6b), i.e. installation of a long curtain over AFC and walkway region of the chock shield at $2-5 \mathrm{~m}$ upstream of the TG motor. As discussed previously, $\mathrm{U}$ ventilation system is used in Mine A, with face quantity of around $90 \mathrm{~m} 3 / \mathrm{s}$. The results of the simulations showing the effect of this curtain configuration on air velocity and methane gas distribution patterns near the TG corner area are presented in Figure 7. The curtain configuration is also shown in Figure 7 , as inset figure.

The gas distribution patterns presented in Figure 7a shows that the methane gas concentration level is around $0.4-0.7 \%$ at the TG motor area, with this curtain configuration. The methane gas concentration at the TG motor area is still close to the $1.0 \%$ statutory limit. The velocity distribution presented in Figure $7 \mathrm{~b}$ shows that the 
installation of long curtain results in very high turbulence and recirculation zones around the curtain and around the TG motor area. Analyses of the results indicate that even minor disturbances in the panel may result in gas concentration levels rising over 1.0\% at the TG motor area. The results indicate that this curtain configuration may not be a best control option as its effectiveness in controlling methane gas concentration levels at TG motor seems to be uncertain.

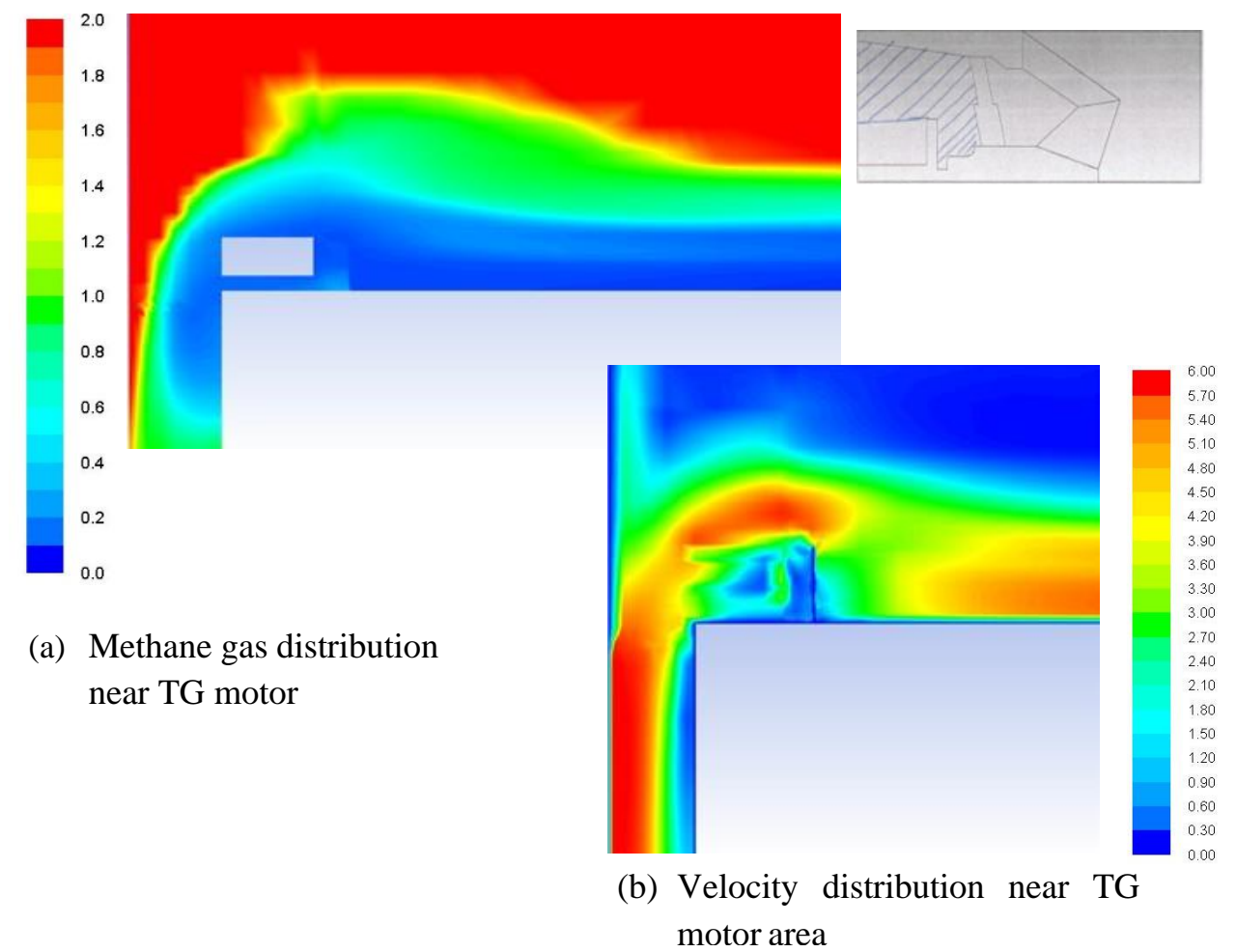

Figure 7 Methane gas and velocity distribution with curtain above AFC and walkway -

Mine A

This control option 2 involves configuration 3 (Figure 6c), i.e. installation of a curtain in the walkway region of the chock shield at $2-5 \mathrm{~m}$ upstream of the TG motor. The results of the simulations showing the effect of this curtain configuration on air velocity and methane gas distribution patterns near the TG corner area are presented in Figure 8. The curtain configuration is also shown in the inset figure.

The gas distribution patterns presented in Figure 8a shows that the methane gas concentration level is below $0.3 \%$ at the TG motor area, with this curtain configuration. The velocity distribution presented in Figure $8 \mathrm{~b}$ shows that the installation of walkway curtain results in splitting of airflow and diversion of significant stream of airflow into the goaf region. Results indicate that this diversion of airstream into the goaf assists in 
moving/pushing the gas fringe away from the TG motor area. There was no recirculation zone formation around the curtain. Analyses of the results indicate that this curtain configuration would be effective in significantly reducing methane gas concentration levels around the TG motor region. However, results also show that gas fringe with gas concentration levels above $1.0 \%$ is close to the TG motor area even after installation of this curtain. It is to be noted here that optimal positioning of this curtain configuration is also important to control gas concentration levels near the TG motor. The curtain should be located at about $2-5 \mathrm{~m}$ upstream of the TG motor location.

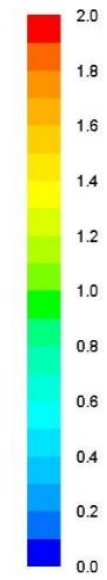

(a) Methane gas distribution near TG motor

2
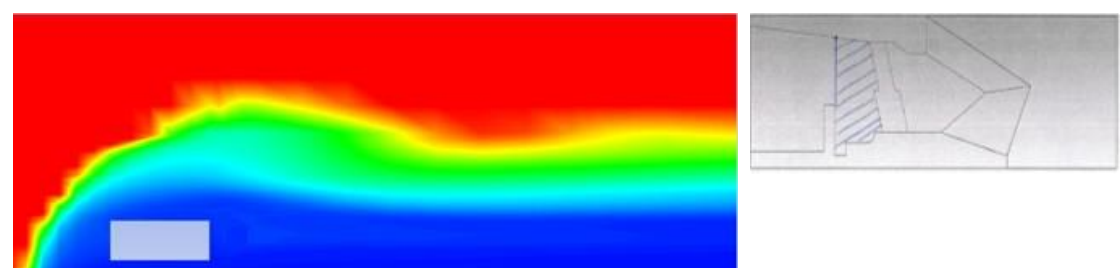

\section{.}

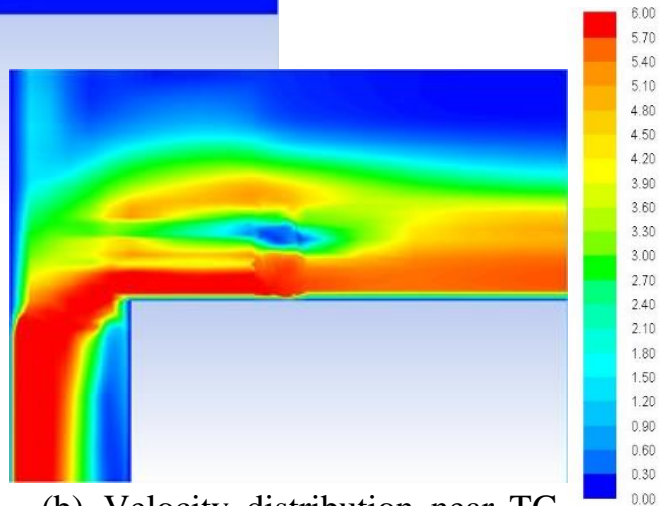

(b) Velocity distribution near TG motor area

Figure 8 Methane gas and velocity distribution with curtain in the walkway - Mine A

This control option 3 involves a combination of configurations 3 and 4 (Figure $6 c \& d$ ), i.e. installation of a curtain in the walkway region of the chock shield at $2 \mathrm{~m}$ upstream of the TG motor and an additional curtain in the walkway region of the transition shields adjacent to the TG motor. The results of the simulations showing the effect of this curtain configuration on air velocity and methane gas distribution patterns near the TG corner area are presented in Figure 9. The curtains configuration in two chock shields, i.e. in standard shield and in transition shield, is also shown in the inset figure.

The gas distribution patterns presented in Figure 9a shows that the methane gas concentration level is below $0.2 \%$ at the TG motor area, with this curtain configuration. Methane gas distribution results also shows that high concentration gas fringe is moved away by a few meters (around 3 to $5 \mathrm{~m}$ ) from the TG motor location. The velocity distribution presented in Figure 9b shows that the installation of two walkway curtains 
in two chock shields results in splitting of airflow and diversion of significant stream of airflow into the goaf region. Results indicate that this diversion of airstream into the goaf assists in pushing/moving the gas fringe further away from the TG motor area. There was no recirculation zone formation around the curtain. Analyses of the results indicate that this curtains configuration would be very effective in significantly reducing methane gas concentration levels around the TG motor region. It is to be noted here that optimal positioning of these curtains configuration is also important to control gas concentration levels near the TG motor.

To investigate the effect of ventilation airflow quantity on the effectiveness of various face gas control strategies, additional simulations were carried out with reduced ventilation under Mine A conditions. In the original simulation, the face ventilation was around $90 \mathrm{~m}^{3} / \mathrm{s}$. In the second simulation, the face ventilation quantity was reduced to 50 $\mathrm{m}^{3} / \mathrm{s}$. In both the cases, $\mathrm{U}$ ventilation was employed during modelling simulations.

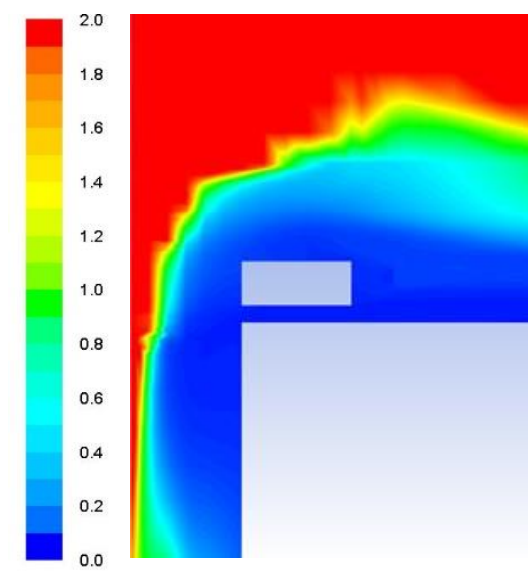

(a) Methane gas distribution near TG motor
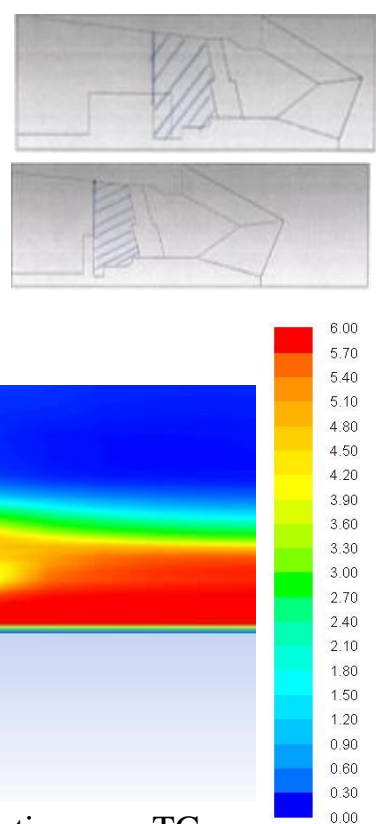

(b) Velocity distribution near TG motor area

Figure 9 Methane gas and velocity distribution with two curtains, walkway and near TG motor - Mine A

The results of the simulations under $90 \mathrm{~m}^{3} / \mathrm{s}$ airflow conditions showing the effect of the walkway curtain configuration on air velocity and methane gas distribution patterns near the TG corner area are presented in Figure 10. The curtain configuration is also shown in the inset figure. The gas distribution patterns presented in Figure 10a shows that the methane gas concentration level is below $0.3 \%$ at the TG motor area with this curtain 
configuration under high airflow conditions of $90 \mathrm{~m} / \mathrm{s}$. The velocity distribution presented in Figure 10b shows that the installation of walkway curtain results in splitting of airflow and diversion of significant stream of airflow into the goaf region under high airflow conditions. Results indicate that this diversion of airstream into the goaf assists in moving/pushing the gas fringe away from the TG motor area. Analyses of the results indicate that this curtain configuration would be effective in significantly reducing methane gas concentration levels around the TG motor region under high face airflow conditions.

The results of the simulations under $50 \mathrm{~m} / \mathrm{s}$ airflow conditions showing the effect of the walkway curtain configuration on air velocity and methane gas distribution patterns near the TG corner area are presented in Figure 11. The curtain configuration is also shown in the inset figure. The gas distribution patterns presented in Figure 11a shows that the methane gas concentration level is around $0.6 \%$ to $0.8 \%$ at the TG motor area with this curtain configuration under low airflow conditions of $50 \mathrm{~m}^{3} / \mathrm{s}$. The velocity distribution presented in Figure 11b shows that the installation of walkway curtain results in splitting of airflow and diversion of a low air velocity stream into the goaf region under low airflow conditions. Results indicate that this diversion of airstream into the goaf assists in moving/pushing the gas fringe a little bit away from the TG motor area. Analyses of the results indicate that this curtain configuration would not be very effective in significantly reducing methane gas concentration levels around the TG motor region under low face airflow conditions.

Analyses and comparison of the results indicate that the walkway curtain control strategy seems to be less effective in reducing methane gas concentration levels around the TG motor region under the reduced airflow conditions, when compared with its effectiveness under high airflow conditions. Analyses of the results also indicate that gas concentration levels around the TG motor area would be significantly higher under reduced face ventilation conditions, with TG motor area surrounded by $0.6 \%$ to $0.8 \%$ methane gas concentration levels. 


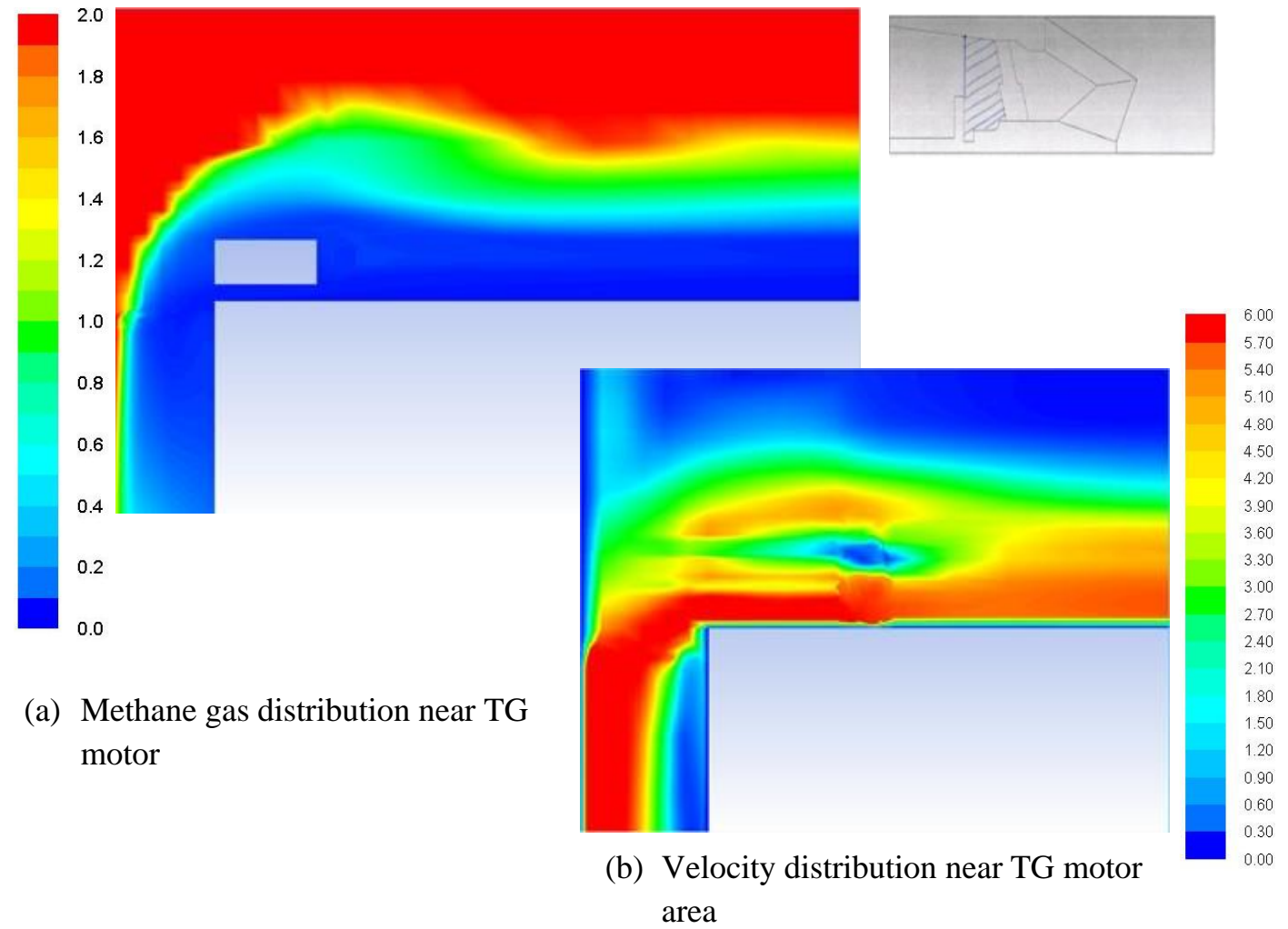

Figure 10 Methane gas and velocity distribution with curtain in the walkway, Mine A - 90 $\mathrm{m}^{3} / \mathrm{s}$ 


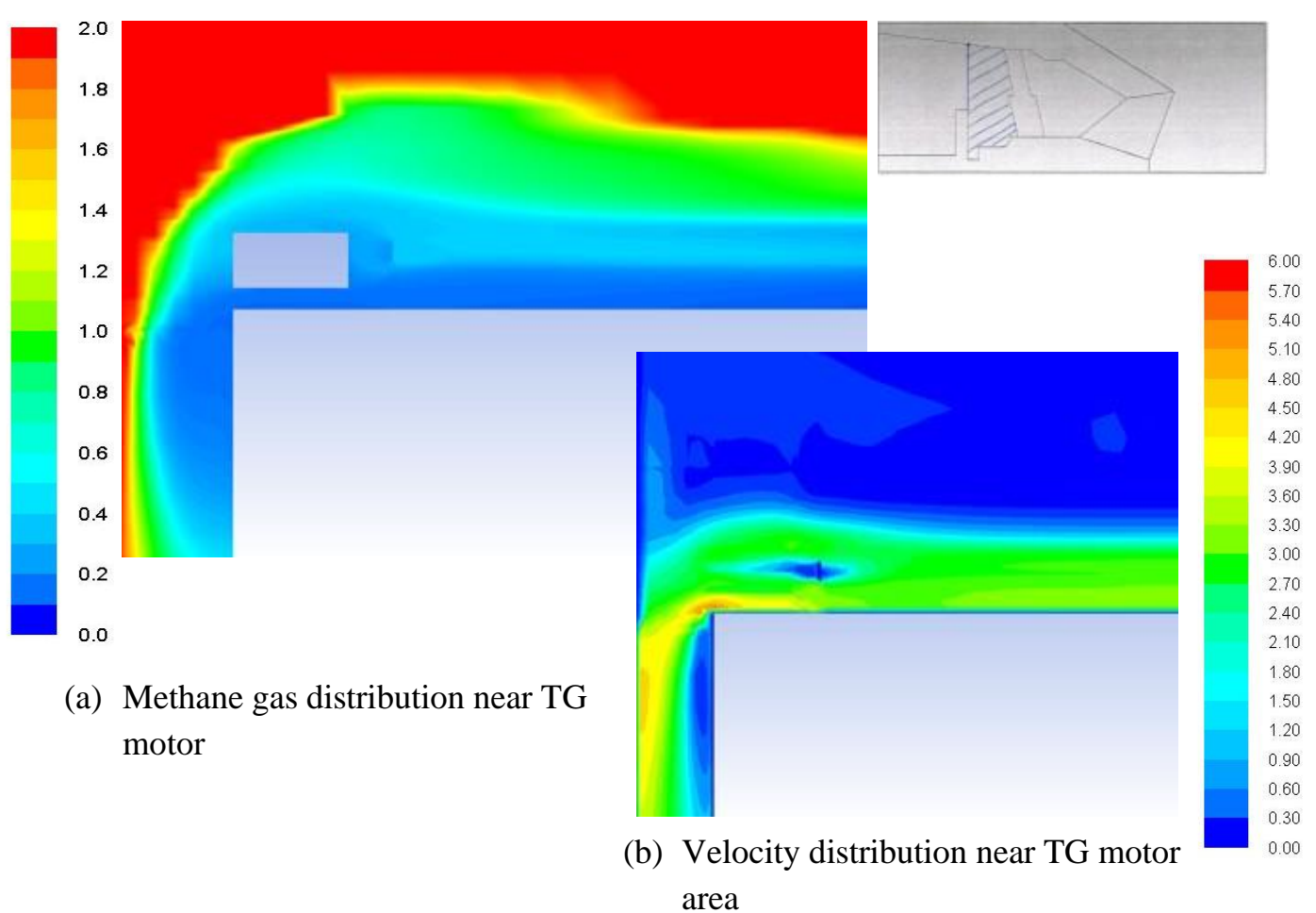

Figure 11 Methane gas and velocity distribution with curtain in the walkway, Mine A - 50 $\mathrm{m}^{3} / \mathrm{s}$

\section{CONCLUSIONS}

A brief summary of the study findings and recommended face gas control strategies are as follows:

- Results of Mine A simulations show that the gas concentration levels over the TG motor area would be around $0.7 \%-0.8 \%$, and the gas fringe with gas concentration levels above $1.0 \%$ would be very close to the TG motor area.

- Analyses of the results indicate that the control option involving a combination of curtain configurations would be successful in reducing the gas concentration levels near the TG motor area under Mine A conditions.

- The optimum curtain configuration should include installation of a curtain in the walkway region of the chock shield at $2 \mathrm{~m}$ upstream of the TG motor, and an additional curtain in the walkway region of the transition shields adjacent to the TG motor. 
- Analyses of results indicate that the installation of these curtains would result in splitting of airflow and diversion of significant stream of airflow into the goaf region, and would assist in pushing the gas fringe further away from the TG motor area.

- $\quad$ Analyses of the results indicate that the walkway curtain control strategy would be significantly less effective in reducing methane gas concentration levels around the TG motor region under high cutting height conditions, when compared with its effectiveness under low cutting height conditions.

- Analyses of the results also indicate that the walkway curtain configuration would not be very effective in diverting significant airflow towards the goaf side, and in reducing the methane gas concentration levels around the TG motor under reduced airflow/ low air velocity conditions.

To address the issue of significant gas delays due to high methane gas concentration levels near the tailgate (TG) motor area of the longwall face, detailed CFD models of longwall face were developed for Mine A. Results of Mine A simulations show that the gas concentration level at the TG motor area is around $0.7 \%$, and the gas fringe with gas concentration levels above $1.0 \%$ is very close to the TG motor area. Analyses of the results indicate that even minor disturbances in panel, such as change in barometric pressures or minor ventilation changes due to TG collapse and any reductions in face ventilation may result in gas concentration levels rising over $1.0 \%$ at the TG motor area.

\section{ACKNOWLEDGEMENTS}

The authors would like to record their grateful thanks to ACARP for funding and providing support to this research over the years. The authors wish to express their sincere appreciation to the Anglo Metallurgical Coal company management and staff for their support in providing the necessary field data. We would also like to thank the management of CSIRO for their support to the project.

\section{REFERENCES}

AZIZ, N., SRINIVASA, R.B. AND BAAFI, E. (1993) Application of Computational Fluid Dynamics Codes to Develop Effective Gas/Dust Control Measures in Underground Coal Mines, The Australian Coal Journal, No42, p19-27.

BALUSU, R. et al. (2002) An investigation of the gas flow mechanics in longwall goafs, In: 9th US Mine Ventilation Symposium, Kingston, Ontario, Canada, June 2002 
BALUSU, R. et al. (2004) Optimisation of goaf gas drainage and control strategies ACARP Project C10017, CSIRO Exploration and Mining Report 1186F, June 2004

HUANG, J., BRUINING, J. AND WOLF, K.H. (2001) Modeling of gas flow and temperature fields in underground coal fires. Fire Safety Journal, 36 (5) pp. 477-489.

TREVITS, M.A. et al. (2009) Understanding mine fires by determining the characteristics of deep-seated fires. NIOSH Document.

PROUD, D., COLLECUTT, G. AND HUMPHREYS, D. (2015) Computational fluid dynamics modelling of coal dust explosions and suppression systems. In: Third Australian Mine Ventilation Conference. The Australasian Institute of Mining and Metallurgy, Sydney, Australia, pp. 309- 313.

COLLECUTT, G., HUMPHREYS, D. AND PROUD, D. (2009) CFD simulation of underground coal dust explosions and active explosion barriers. In: 7th International Conference on CFD in the Minerals and Process Industries. pp. 1-6.

MOLONEY, K.W., HARGREAVES, D.M. AND LOWNDES, I.S. (1998) Computational fluid dynamics (CFD) simulations in underground auxiliary ventilated headings. In: Computer applications in the minerals industries. International symposium, United Kingdom, pp. 721-731.

BRUNE, J.F. and SAKI, S.A. (2017) Prevention of gob ignitions and explosions in longwall mining using dynamic seals. International Journal of Mining Science and Technology 27 (6), pp. 999-1003.

YUAN, L. and SMITH, A.C. (2009) CFD modeling of spontaneous heating in a largescale coal chamber. Journal of Loss Prevention in the Process Industries 22 (4), pp. 426433.

YUAN, L. and SMITH, A.C. (2009) Numerical Study on Spontaneous Combustion of Coal in US. In: Proceedings of the Ninth International Mine Ventilation Congress, New Delhi, India, November 10-13 2009.

FLETCHER, C.A.J., et al. (1995) Computational simulation for mineral processing. In: Proceedings APCOM XXV, Australia, pp. 361-370.

TANGUTURI, K., and BALUSU, R. (2014) CFD Modeling of Methane Gas Distribution and Control Strategies in a Gassy Coal Mine. The Journal of Computational Multiphase Flows, 6(1), pp. 65-77.

PATANKAR V. SUHAS. (1980) Numerical Heat Transfer and Fluid Flow. Washington DC: Hemisphere Publishing Corp., 1980 